\title{
Statistical Analysis of Deep Drilling Process Conditions Using Vibrations and Force Signals
}

\author{
Hazwan Syafiq $^{1}$, M.A.N. Kamarizan ${ }^{1}$, M.F. Ghazali ${ }^{2}$ and A.R Yusoff ${ }^{1, \text { a }}$ \\ ${ }^{1}$ Faculty of Manufacturing Engineering, Universiti Malaysia Pahang, 26600, Pekan, Pahang \\ ${ }^{2}$ Faculty of Mechanical Engineering, Universiti Malaysia Pahang, 26600, Pekan, Pahang
}

\begin{abstract}
Cooling systems is a key point for hot forming process of Ultra High Strength Steels (UHSS). Normally, cooling systems is made using deep drilling technique. Although deep twist drill is better than other drilling techniques in term of higher productivity however its main problem is premature tool breakage, which affects the production quality. In this paper, analysis of deep twist drill process parameters such as cutting speed, feed rate and depth of cut by using statistical analysis to identify the tool condition is presented. The comparisons between different two tool geometries are also studied. Measured data from vibrations and force sensors are being analyzed through several statistical parameters such as root mean square (RMS), mean, kurtosis, standard deviation and skewness. Result found that kurtosis and skewness value are the most appropriate parameters to represent the deep twist drill tool conditions behaviors from vibrations and forces data. The condition of the deep twist drill process been classified according to good, blunt and fracture. It also found that the different tool geometry parameters affect the performance of the tool drill. It believe the results of this study are useful in determining the suitable analysis method to be used for developing online tool condition monitoring system to identify the tertiary tool life stage and helps to avoid mature of tool fracture during drilling process..
\end{abstract}

\section{Introduction}

Drilling is the most familiar machine tool operations in manufacturing technology over the time. Almost 75 percent of metal cutting operations are still carried out by conventional twist drills [1]. Since the industry has allocated a plentiful amount of money on drilling tools, the idea to decrease the production cost in drilling operation is realized by introducing of deep drilling process. In this technique, the hole can be drilled at least 10 times of the diameter of drill bit which allow producing a deeper hole [2]. There are several deep drilling techniques that been applied in industry such as boring trepanning association drill, the ejector drilling systems and gun drill. However there are alternative techniques have proposed by researchers to overcome the weakness of deep drill methods called deep twist drilling technique. Deep twist drilling can reduce the production time using high speed and feed rate compared to the other deep drilling techniques. Based on current research of hot forming, it is found that technique of deep twist drilling can improve the cooling rate. By increasing cutting length capability of drill tool to increase the cooling energy efficient that can reduce the number of hot forming die blocks. However, one of primary issues in deep twist drilling technique is premature tool breakage; due to the tool wear, chip clogging and deflection which can affect sustainability of the process. Therefore, there is a need for more clear understanding of deep twist drill phenomena.

Statistical parameters are established method applied in research analysis. Through the implementation of statistical analysis it can improve the process understanding, enhanced level of control and thus contribute in reduces process variability and improved the output quality [3]. There are several numbers of statistical parameters such as root mean square (RMS), arithmetic mean, standard deviation, variance and kurtosis etc. It has been employed widely in manufacturing process analysis activities. Ghoreishi et al. [4] applied variance to analyze the interactions between six controllable variables on the hole taper and circularity in laser percussion drilling. Variance through implementation of ANOVA also use to studies the effect of drilling parameters such as cutting speed, feed rate, point angle and diameter of tool drill $[5,6]$. Meanwhile, Gaja [7] implemented RMS to analyze data depth-of-cut detection and tool-workpiece engagement by using acoustic emission monitoring system during milling machining. RMS values also were used to classified tool wear levels in lathe, milling and drilling machines $[8,9$, and 10]. Kurtosis and skewness of vibration signal data also be implemented to indicate the different types of drill wear [11].

Jantunen et al. [12] compared seven statistical parameters such as RMS, skewness, kurtosis, mean,

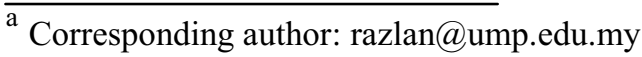


arithmetic mean, maximum and minimum in tool wear measurement case study. Based on comparison, it found that RMS value is appropriate parameters to represent the case study data. Patrick [13] in his thesis compared six statistical parameters: mean, peak, RMS, variance, crest factor and kurtosis in study the signals pattern of a sharp drill and a worn drill. Results reveal that, four parameters which are RMS, peak, crest factor and the kurtosis are capable to evaluate the patterns and the levels of different measured signals. However, it also found that peak is not suitable to be applied in drilling operation due to stochastic drill behavior and peak level is not an averaging statistical value. It is summarized that better results could be initiated by considering derivative factors such as crest factor and kurtosis. Xu [14] implemented several statistical parameters to find the relations between the drilling process conditions with several machining parameters such as workpiece material, drill diameter, spindle speed, feedrate and the drill corner wear. Statistical parameters applied are mean, RMS, delta and standard deviation features. Based on analysis, in term of material, spindle speed, feed rate and drill diameter comparison, it found that data produce by mean and RMS is almost similar but differs to delta features due to statistical algorithm. Meanwhile others parameters have clear distinguish values especially in feedrate comparison. It is concluded that mean and RMS are very similar in the values and variation forms, thus, some of them can be eliminated for remove of redundancy.

Based on the review, it can summarize that, a lot of study especially in drilling activities has been conducted by using statistical parameters analysis. Even though there is no any statistical analysis of deep drilling case study found, it is believes that the conceptual stages and methodology will be same as standard drilling. This paper discusses the identification of deep twist drill tool condition when different machining parameters, such as cutting speed, feed rate and depth of cut are applied. The identification is done through several statistical parameters; root mean square (RMS), mean, kurtosis, standard deviation and skewness. It is then been compared to find the most suitable statistical parameters that can represent tool condition behavior. In this study, it also leads to the finding of suitable machining parameters and tool geometry that can be used in deep twist drill in order to get maximum deep-hole drilling capability.

\section{Experimental setup}

The deep twist drilling condition experiments are carried out on a 3-axis CNC vertical machine (HAAS CNC Vertical Machine). The tool employed are high speed steel, HSS long series twist drills with diameter $8 \mathrm{~mm}$, overall length $165 \mathrm{~mm}$ and flute length $109 \mathrm{~mm}$. Since this is an initial study, it is good to start with a standard geometry of tool drill, as tabulated in Table 1. Based on literature review conducted, there is no study that focus on the performance of this tool even tough manufacturer keep produces and promote this types of geometry. Die material, SKD 61 are used in this study. It is a hard-to-cut material with HRC ranges 50-55 in die and mold field. The work piece is cut into block with size of $90 \mathrm{~mm} \mathrm{x} 70$ $\mathrm{mm} \times 80 \mathrm{~mm} .25$ holes are drilled in a block that held in a vice on top of the dynamometer. Each of holes are drilled by using different cutting conditions such as cutting speed, feed rate and depth of cut from design of experiment, as listed in Table 2. The summaries of cutting condition ranges used in design of experiment, DOE are referred from data used by others researcher and data provided by tool manufacturer. Experiments are divided into 5 regions which represent number of cutting speed. This experiment is repeated to 3 times to get the reliable results. All boreholes were pre-center using pilot drills with diameter $8 \mathrm{~mm}$ and $1.5 \mathrm{~mm}$ depth. This can minimize the effects associated with tool run-out [15].

Meanwhile, for data acquisition, force and vibration sensors are mounted to the workpiece and spindle machine, as shown in Figure 1. Dynamometer; model Kistler 9257B with built-in 3 axis charge amplifier attached on the work piece. Meanwhile for vibration, the tri-axial accelerometer (Model 356B21) with sensitivity of $+10 \mathrm{mV} / \mathrm{g}$ is attached to spindle machine. The analog signals from these sensors were fed into data acquisition board, DAQ with 2000 of sampling rate capability. Meanwhile, for experiments to compare between two tool geometry, holes with optimum results of tool condition from previous experiment are repeated again by other tool geometry such as point angle, helix angle, web thickness and relief angle. Collected data are compared and analyzed. Details for both tool drills specifications are provided in Table 1.

Table 1. Long twist drill series specifications and process parameters.

\begin{tabular}{|c|c|c|c|c|c|}
\hline Tool & $\begin{array}{c}\text { Manufacturer } \\
\text { tool type }\end{array}$ & Substrate & $\begin{array}{c}\text { Point } \\
\text { angle }\end{array}$ & $\begin{array}{c}\text { Helix } \\
\text { angle }\end{array}$ & $\begin{array}{c}\text { Flute } \\
\text { shape }\end{array}$ \\
\hline 1 & $\begin{array}{c}\text { Sherwood SHR- } \\
025\end{array}$ & HSS & $118 \circ$ & $35^{\circ}$ & Standard \\
\hline 2 & OSG & $\begin{array}{c}\text { Solid } \\
\text { Carbide }\end{array}$ & $120^{\circ}$ & $40 \circ$ & $\begin{array}{c}\text { Wide } \\
\text { flutes }\end{array}$ \\
\hline
\end{tabular}

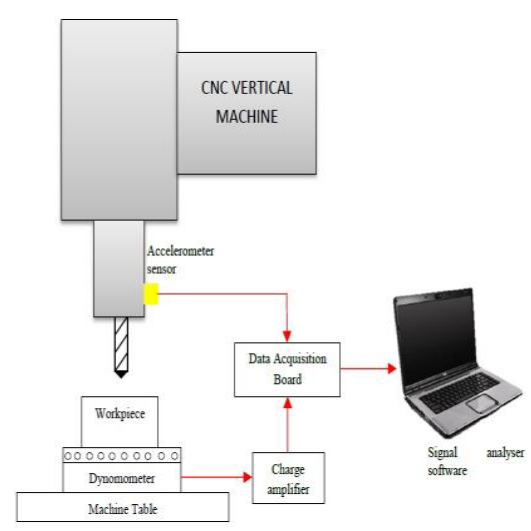

a). Schematic diagram 


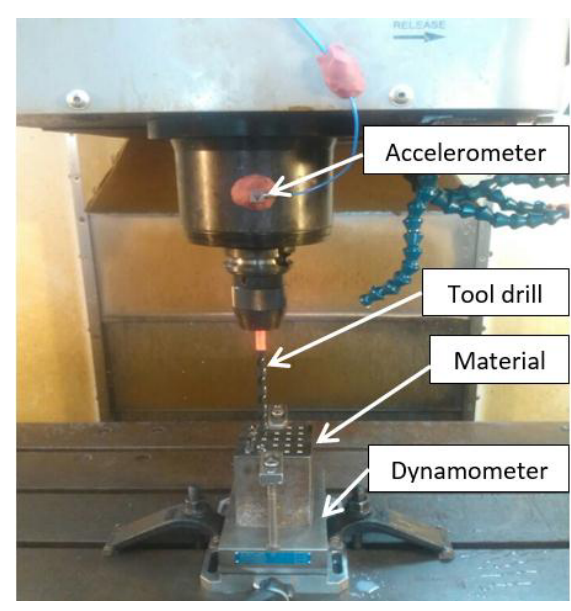

b). Experimental setup

Figure 1. The schematic diagram and actual setup of experiment.

Table 2. Cutting conditions for 25 experiment.

\begin{tabular}{|c|c|c|c|c|}
\hline Experiment & Region & $\begin{array}{c}\text { Cutting } \\
\text { speed } \\
\text { (m/min) }\end{array}$ & $\begin{array}{l}\text { Feedrate } \\
\text { (mm/rev) }\end{array}$ & $\begin{array}{c}\text { Depth of } \\
\text { cut } \\
(\mathrm{mm})\end{array}$ \\
\hline 1 & \multirow{5}{*}{1} & 30 & 0.10 & 40 \\
\hline 2 & & 30 & 0.15 & 50 \\
\hline 3 & & 30 & 0.20 & 60 \\
\hline 4 & & 30 & 0.25 & 70 \\
\hline 5 & & 30 & 0.30 & 80 \\
\hline 6 & \multirow{5}{*}{2} & 40 & 0.10 & 50 \\
\hline 7 & & 40 & 0.15 & 60 \\
\hline 8 & & 40 & 0.20 & 70 \\
\hline 9 & & 40 & 0.25 & 80 \\
\hline 10 & & 40 & 0.30 & 40 \\
\hline 11 & \multirow{5}{*}{3} & 50 & 0.10 & 60 \\
\hline 12 & & 50 & 0.15 & 70 \\
\hline 13 & & 50 & 0.20 & 80 \\
\hline 14 & & 50 & 0.25 & 40 \\
\hline 15 & & 50 & 0.30 & 50 \\
\hline 16 & \multirow{5}{*}{4} & 60 & 0.10 & 70 \\
\hline 17 & & 60 & 0.15 & 80 \\
\hline 18 & & 60 & 0.20 & 40 \\
\hline 19 & & 60 & 0.25 & 50 \\
\hline 20 & & 60 & 0.30 & 60 \\
\hline 21 & \multirow{5}{*}{5} & 70 & 0.10 & 80 \\
\hline 22 & & 70 & 0.15 & 40 \\
\hline 23 & & 70 & 0.20 & 50 \\
\hline 24 & & 70 & 0.25 & 60 \\
\hline 25 & & 70 & 0.30 & 70 \\
\hline
\end{tabular}

\section{Statistical measurement}

In order to analyze data generated by dynamometer and accelerometer sensors, fives statistical parameters are been applied and compared. These parameters are the root mean square (RMS), mean $\mu$, standard deviation $\sigma$, kurtosis $\mathrm{K}$ and the skewness $\mathrm{S}$. These parameters can be calculated using the following formula as referred in [11].

Mean $(\mu)$ calculates the force and vibration signals average for $\mathrm{N}=2000$ samples:

$$
\mu=\frac{1}{N} \sum_{i=1}^{N} x_{i}
$$

Root mean square (RMS) is the most common parameter used in statistical analysis [16]. Its value contains all the energy in the signal and therefore also all the noise and all elements that depend on the cutting process. RMS defined as:

$$
R M S=\sqrt{\frac{1}{N} \sum_{i=1}^{N} x_{i}^{2}}
$$

where $x_{i}$ refer to instantaneous amplitude of the signal from force and vibration. Meanwhile for standard deviation $(\sigma)$, the data was standardized by $\left(x_{i}-\mu\right)$ and it is the mean square value about the mean:

$$
\sigma=\sqrt{\frac{1}{N} \sum_{i=1}^{N}\left(x_{i}-\mu\right)^{2}}
$$

Next, the kurtosis $(\mathrm{K})$ is a measure of how outline-prone a distribution [17]. Based on Issam [11] the normal distribution of kurtosis is 3. Meanwhile for distribution that is more or less outliner-prone having kurtosis greater or less than 3. Kurtosis defined as:

$$
K=\frac{1}{N} \sum_{i=1}^{N} \frac{\left(x_{i}-x\right)^{4}}{\sigma^{4}}
$$

Where $x$ is average of force and vibration amplitude or mean, $\mu$. In term of analysis, it found that kurtosis was rather sensitive to the occurrence of spikes or impulses in the time domain of the vibration signal [18]. Skewness (S) is a measure of the asymmetry of the data around the sample mean. Skewness defined as:

$$
S=\frac{E(x-\mu)^{3}}{\sigma^{3}}
$$

Where $E(x)$ is the expected value of $x$. In the next section, results from experiments are analyzed and discuss.

\section{Results and discussion}

\subsection{Analysis of tool condition behavior}

Figure 2 and 3 show the tools condition behavior based on five statistical analyses for vibrations and forces. Tool condition are been classify into three category; good, fracture and blunt. Based on tool condition, only 6 out of 25 holes are capable to finish without failures. Experiments number 1, 2, 3, 4, 6 and 7 are in category good condition meanwhile others are in blunt and fracture categories. The highest cutting speed that can be adapted through standard long series twist drill tool (Sherwood SHR-025) is through experiment number 7 with 40 $\mathrm{m} / \mathrm{min}$, feed rate $0.15 \mathrm{~mm} / \mathrm{rev}$ and depth of cut $60 \mathrm{~mm}$. 
Meanwhile the highest feed rate that can be adapted is $0.25 \mathrm{~mm} / \mathrm{rev}$ with cutting speed $30 \mathrm{~m} / \mathrm{min}$ and depth 70 $\mathrm{mm}$ through experiment number 4 . In term of deep drilling definition, ratio between length to diameter L/D must be at least 10 [1]. Through cutting parameter experiment number 7 , it only can achieve 8.75 ratio of $\mathrm{L} / \mathrm{D}$, where it not enough to stand as deep drilling theory. However, based on pattern shown by experiment number 6; average value of it vibration is the lowest. It is found that the depth can be increased from $50 \mathrm{~mm}$ to $80 \mathrm{~mm}$ to achieve L/D 10. Due to that, cutting condition of experiment number 6 will be used for experiment of tool geometry comparison by changing its depth from 50 to $80 \mathrm{~mm}$.

\subsection{Statistical analysis data of vibration and force}

Based on data observation, it found that data vibrations recorded by accelerometer more details on the tool deflection meanwhile data captured via dynamometer influenced by chip clogging. In term of selection of appropriate statistical parameter, it is chosen by considering several theories. Such validation with time domain graph pattern generated by sensors and the relationship between cutting condition to the statistical graph generated. In Table 3, it can be seen that all vibrations statistical data except skewness, are capable to differentiate between good and blunt condition according to the statistical ranges for experiments number 1 until 10. However, the phenomena were changed when boreholes number 11 to 25 were analyzed. All statistical analysis except kurtosis cannot differentiate between blunt and fracture condition. This is happen due to small number of difference between blunt and fracture data. So, in order to distinguish between this two data, it requires for sensitive analysis methods. Based on Mahfouz [11], it is found that kurtosis was sensitive to the occurrence of spikes or impulses in the time domain of the vibration signal. It capable to differentiate between blunt and fracture data. In Figure 2 (e), if the value of acceleration is exceeding to $17.13 \mathrm{~m} / \mathrm{s} 2$ the tool are in 'blunt' region and if lower than that is in 'good' zone. Meanwhile, if the value exceeding to 28.62 and above tool are in 'fracture' region.

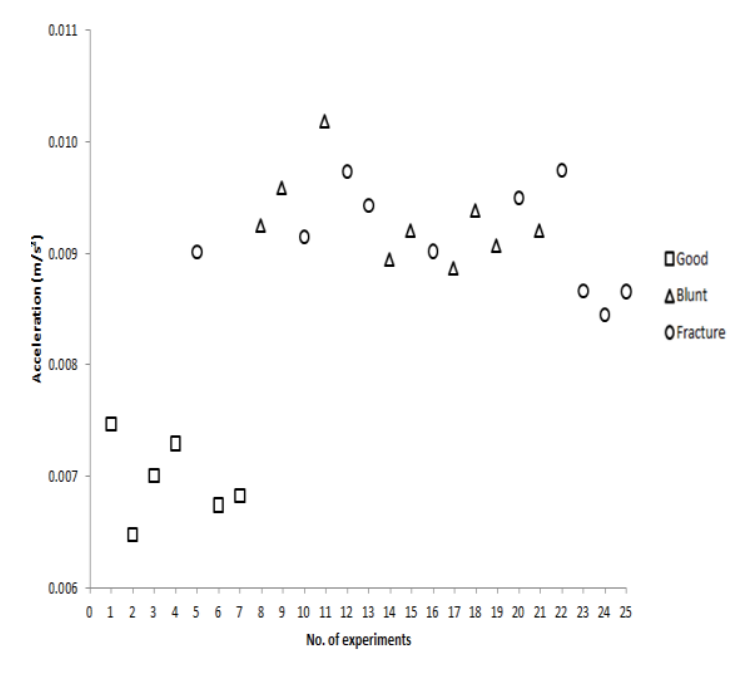

a). Mean analysis

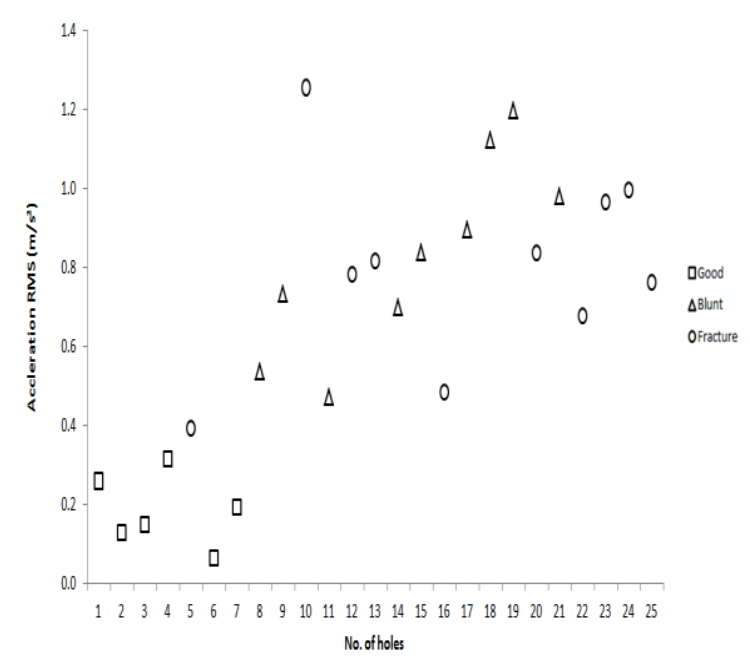

b). RMS analysis

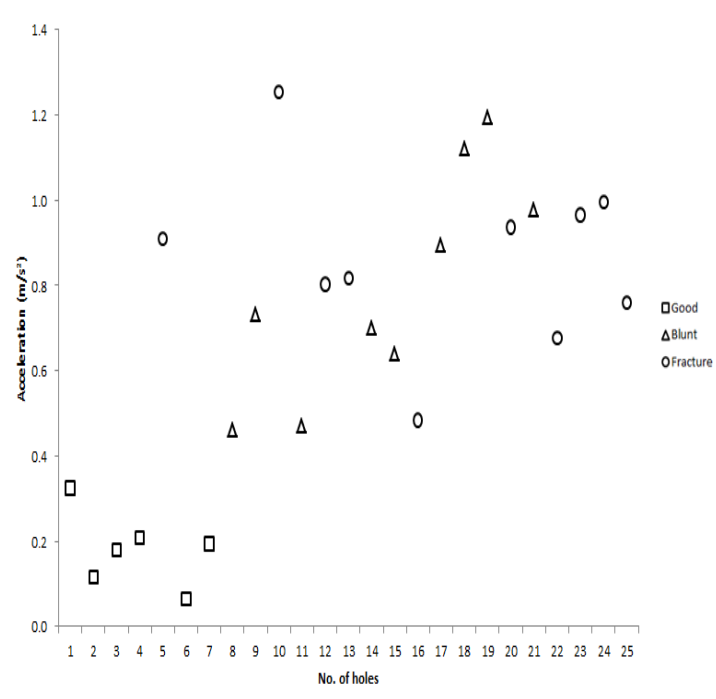

c). Standard deviation analysis 


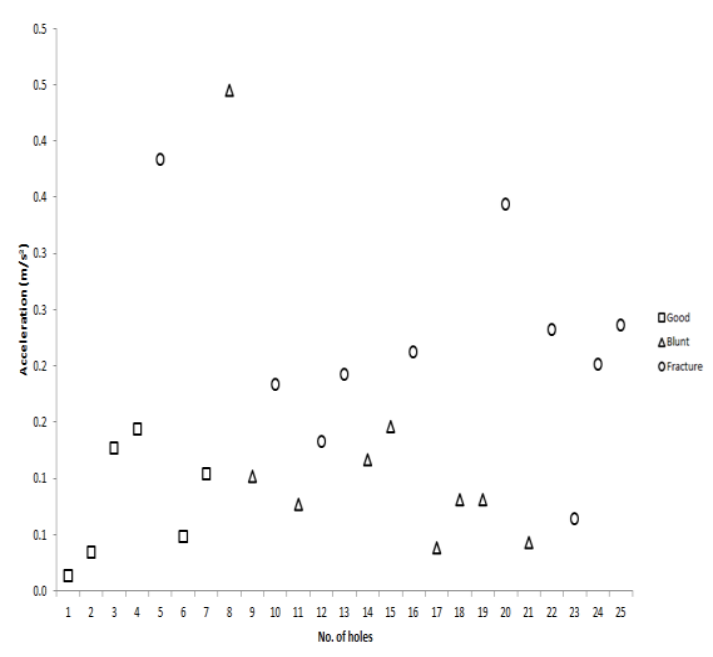

d). Skewness analysis

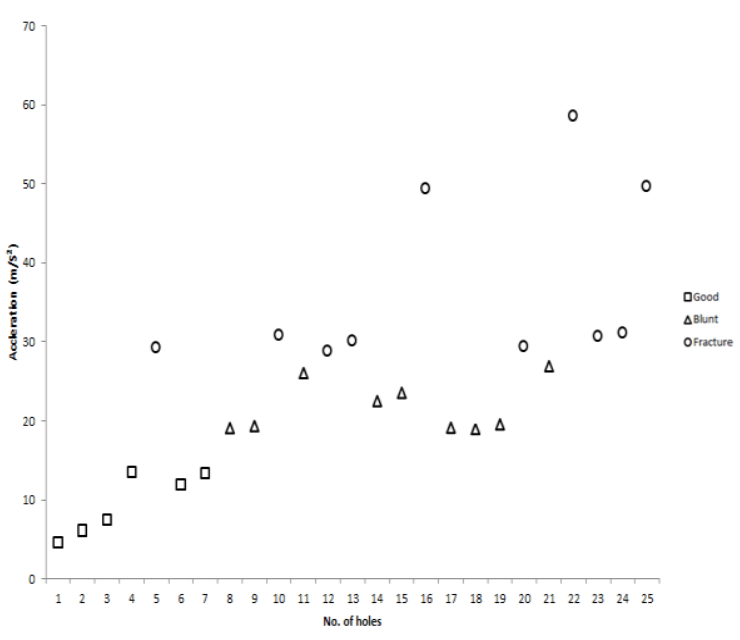

e). Kurtosis analysis

Figure 2(a-e). Statistical analysis of acceleration data

As stated earlier, data captured via dynamometer is influenced by chip clogging. This can be seen in Figure 3 (a-e) at experiments number 1 until 4 where tool are in good condition. It show values are inclining when the depth is increase, due to chip clog. It shows that depth is one of the key players in influencing the forces data. Furthermore, others cutting condition such as cutting speed and feed rate also played role to make chip clogging. For example, when increase the numbers of cutting speeds and feed rate of the machine, its can lead to the growth of amount and size of chips removes and the chances for the tools to break due to chip clogging onto the hole. In Figure 3, it can see that the pattern at experiments number 8 until 25 become blunt and fracture zone. This happens due to the impact from blunt and fracture of the tools. In term of statistical parameter selection, skewness is verified to be the finest gauge of chip clogging, to differentiate between blunt and fracture. It is as indicator there is more closely relation to the changing of cutting conditions. Unlike data produce by acceleration, the range levels of tools conditions for forces are different for every region where it is according to the tools cutting condition as shown in Table 4. For example, in Figure 3 (e) the minimum fracture value for region 3; experiments number 11 until 15 is 4.42 , meanwhile the minimum fracture value for region 4 ; experiments number 16 to 20 is 2.54 . This is happen due to the high differences cutting speed and feed rate. The early breakage of tool in region 4 is because of early chip clogging occurred.

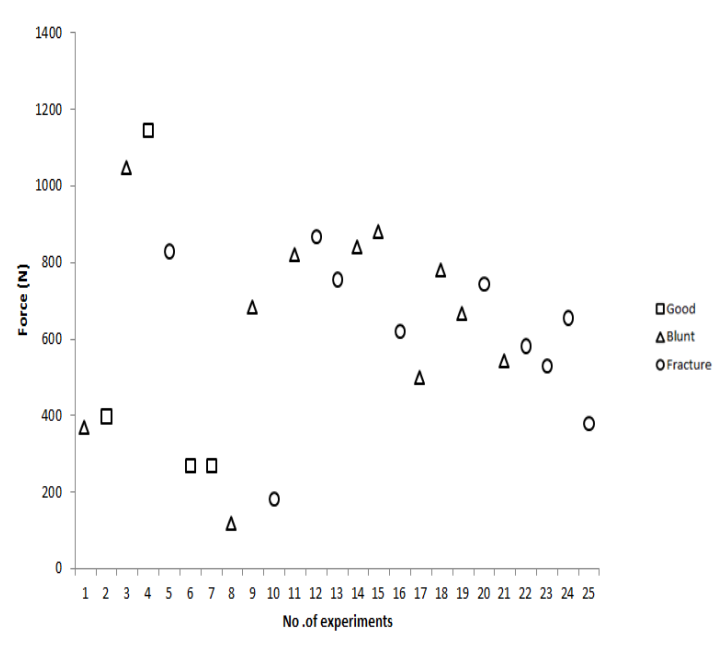

a). Mean analysis

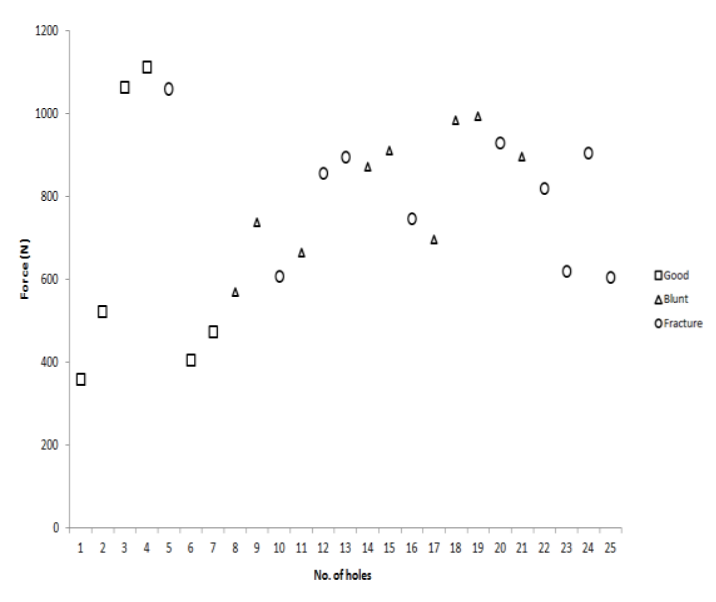

b). RMS analysis 


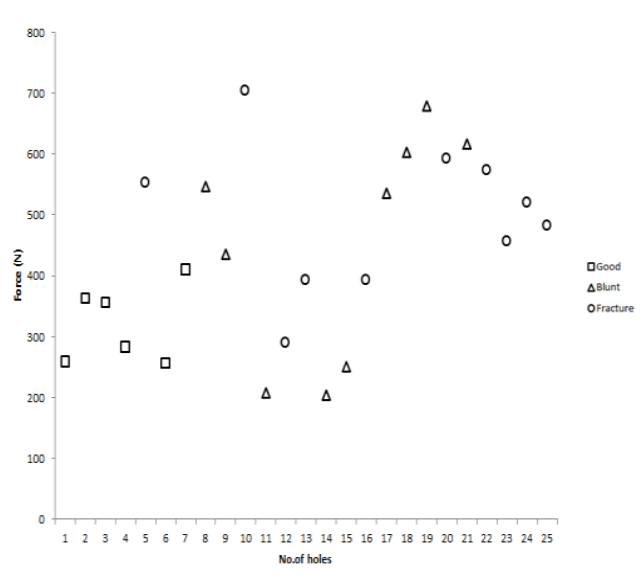

c). Standard deviation analysis

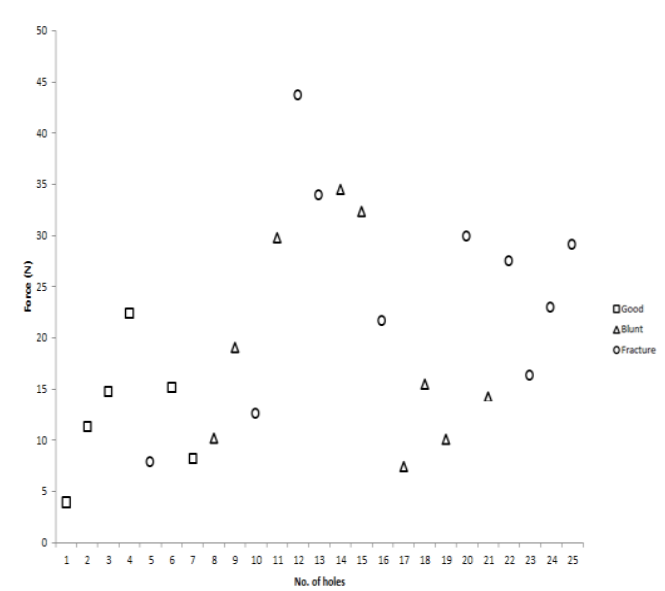

d). Kurtosis analysis

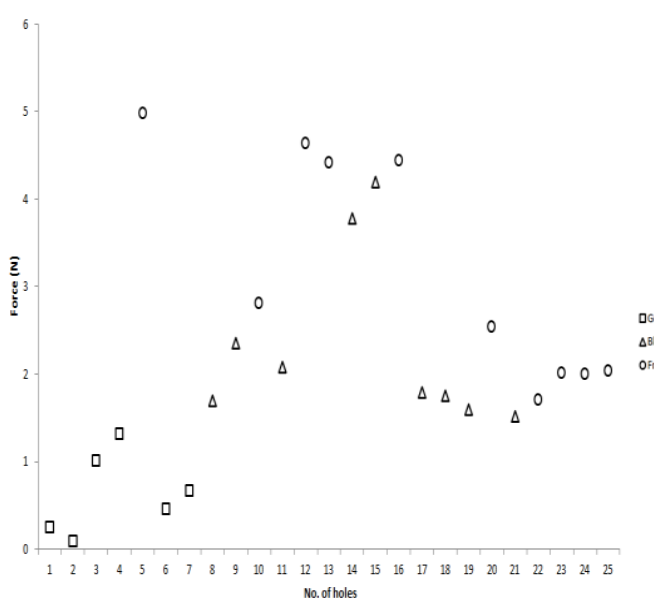

e). Skewness analysis

Figure 3(a-e). Statistical analysis of force data
Table 3. Range of statistical analysis of acceleration data

\begin{tabular}{|c|c|c|c|c|c|}
\hline \multirow{2}{*}{$\begin{array}{c}\text { Tools } \\
\text { condition }\end{array}$} & \multicolumn{5}{|c|}{ Statistical analysis range value } \\
\hline & Mean & RMS & $\begin{array}{l}\text { Standard } \\
\text { Deviation }\end{array}$ & Skewness & Kurtosis \\
\hline & 0.0065 & 0.066 & 0.056 & 0.013 & 4.590 \\
\hline Good & $\begin{array}{c}- \\
0.0075\end{array}$ & $\begin{array}{c}- \\
0.276\end{array}$ & $\begin{array}{c}- \\
0.265\end{array}$ & $\begin{array}{c}- \\
0.144\end{array}$ & $\begin{array}{c}- \\
13.568\end{array}$ \\
\hline Blunt & $\begin{array}{c}0.0089 \\
- \\
0.0102\end{array}$ & $\begin{array}{c}0.469 \\
- \\
1.302\end{array}$ & $\begin{array}{c}0.432 \\
- \\
1.297\end{array}$ & $\begin{array}{c}0.038 \\
- \\
0.445\end{array}$ & $\begin{array}{c}18.981 \\
- \\
26.927\end{array}$ \\
\hline Fracture & $\begin{array}{c}0.0085 \\
- \\
0.0098\end{array}$ & $\begin{array}{c}0.386 \\
- \\
1.249\end{array}$ & $\begin{array}{c}0.474 \\
- \\
1.249\end{array}$ & $\begin{array}{c}0.063 \\
- \\
0.384\end{array}$ & $\begin{array}{c}28.788 \\
- \\
58.542\end{array}$ \\
\hline
\end{tabular}

Table 4. Range of statistical analysis of force data

\begin{tabular}{|c|c|c|c|c|c|c|}
\hline \multirow{2}{*}{$\begin{array}{c}\text { Tool } \\
\text { condition }\end{array}$} & \multirow{2}{*}{ Region } & \multicolumn{5}{|c|}{ Statistical analysis range value } \\
\hline & & $* \mathbf{A}$ & $* \mathbf{B}$ & $* \mathbf{C}$ & $* \mathbf{D}$ & $* \mathbf{E}$ \\
\hline \multirow{3}{*}{ Good } & \multirow{4}{*}{1} & 369.17 & 358.32 & 259.22 & 0.098 & 3.94 \\
\hline & & - & - & - & - & - \\
\hline & & 1093.71 & 1113.3 & 363.17 & 1.31 & 22.39 \\
\hline Fracture & & 852.02 & 1060.6 & 552.59 & 4.98 & 7.84 \\
\hline \multirow{3}{*}{ Good } & \multirow{8}{*}{2} & 239.43 & 404.60 & 256.72 & 0.46 & 8.21 \\
\hline & & - & - & - & - & - \\
\hline & & 272.61 & 474.10 & 410.60 & 0.67 & 15.19 \\
\hline \multirow{3}{*}{ Blunt } & & 150.81 & 569.65 & 435.63 & 1.69 & 10.23 \\
\hline & & - & - & - & - & - \\
\hline & & 626.33 & 736.38 & 546.77 & 2.35 & 19.09 \\
\hline \multirow{2}{*}{ Fracture } & & & 607.70 & & & 12.52 \\
\hline & & 225.511 & 4 & 702.68 & 2.80 & 3 \\
\hline \multirow{3}{*}{ Blunt } & \multirow{6}{*}{3} & 735.13 & 663.97 & 204.14 & 2.08 & 29.8 \\
\hline & & - & - & - & - & - \\
\hline & & 828.89 & 895.14 & 250.99 & 4.19 & 34.52 \\
\hline \multirow{3}{*}{ Fracture } & & 806.29 & 857.08 & 288.81 & 4.42 & 33.87 \\
\hline & & - & - & - & - & - \\
\hline & & 854.49 & 895.14 & 391.73 & 4.63 & 43.66 \\
\hline \multirow{3}{*}{ Blunt } & \multirow{6}{*}{4} & 451 & 696.77 & 250.99 & 1.59 & 7.45 \\
\hline & & - & - & - & - & - \\
\hline & & 880.67 & 993.79 & 679.04 & 4.19 & 32.36 \\
\hline \multirow{3}{*}{ Fracture } & & 713.14 & 746.14 & 391.89 & 2.54 & 21.57 \\
\hline & & - & - & - & - & - \\
\hline & & 714.75 & 929.70 & 591.85 & 4.44 & 29.85 \\
\hline Blunt & \multirow{4}{*}{5} & 620.19 & 895.25 & 616.59 & 1.52 & 14.25 \\
\hline \multirow{3}{*}{ Fracture } & & 425.36 & 606.41 & 456.87 & 1.70 & 16.28 \\
\hline & & - & - & - & - & - \\
\hline & & 723.60 & 929.70 & 591.85 & 2.54 & 29.85 \\
\hline
\end{tabular}

${ }^{*} \mathrm{~A}=$ Mean, ${ }^{*} \mathrm{~B}=\mathrm{RMS},{ }^{*} \mathrm{C}=$ Standard deviation, ${ }^{*} \mathrm{D}=$ Skewness, $* \mathrm{E}=$ Kurtosis

\subsection{Data analysis of different tool geometry}

As explained before, the modification of cutting condition for experiment number 6 with the new depth 80 $\mathrm{mm}$ is used for this experiment. Specifications of tools uses for the comparison are shown in Table 1. Based on the data, as expected the tool is not broken, both tools finish the job smoothly. However, it was found that the value of force for tool 2 is lower than tool 1 up to 34 percent when analyzed through several statistical parameters. This is due to the flutes shape pattern, where 
flutes shape tool 2 is widen compare to tool 1 . Through the widen flutes, the chip flow management is better, and this can allow the tool drill to go deeper. The material of tool 2 also influence the performance where the harden tool material can withstand the impact resulting from the friction between the tool and the surface of the material as well as can prevent from wear. Table 5 shows the values of force for both tools analyze by several statistical parameter.

Table 5. Values of force analyze by statistical parameters

\begin{tabular}{|c|c|c|c|c|c|c|}
\hline Tool & Tool type & Mean & RMS & $\begin{array}{c}\text { Standard } \\
\text { deviation }\end{array}$ & Kurtosis & Skewness \\
\hline 1 & $\begin{array}{c}\text { Sherwood } \\
\text { SHR-025 }\end{array}$ & 497.41 & 589.41 & 283.68 & 5.242 & 1.053 \\
\hline 2 & OSG & 267.84 & 323.15 & 180.28 & 2.758 & 0.693 \\
\hline
\end{tabular}

\section{Conclusion}

In this paper, a summary of tool performances and condition behavior of standard deep twist drill has been given. The signal has been analyzed through several statistical parameters techniques. It was found that data generated by vibrations are more focused on tool deflection meanwhile forces data covered chip clogged. Kurtosis and skewness establish to be appropriate statistical parameters to represent deep twist drill tool conditions for vibrations and forces signals. The results also reveal that the geometry influenced the performance of the tools. Tool with wide flutes can afford for more depth of cut, it also recommended for deep drilling technique. It believe the results of this study are useful in determining the suitable analysis method to be used for developing online tool condition monitoring system to identify the tertiary tool life stage and helps to avoid mature of tool fracture during drilling process.

\section{Acknowledgements}

The authors would like to be obliged to Ministry of Science, Technology and Innovation (MOSTI) and Universiti Malaysia Pahang for providing laboratory facilities and financial assistance under e-science research fund project no. RDU140506.

\section{References}

1. Elzenheimer, J.,Liebeck, T and Tschannerl, M. Noch viel ungenutztes Potenzial beim Bohren. Werkstatt und Betrieb. 2003; 136(11):55-57.

2. Heinemann, R., Hinduja, S., Barrow G .Use of process signals for tool wear progression sensing in drilling small deep holes. International Journal Advance Manufacturing Technology. 2007; 33: 243250

3. Presentetioneze.com. Statistical methods for manufacturing process improvement. Retrived from: http://www.presentationeze.com/blog/statisticalmethods-manufacturing-process improvement/ 15 April 2014
4. Ghoreishi, M., Low, D.K.Y., Li, L. Comparative statistical analysis of hole taper and circularity in laser percussion drilling. International Journal of Machine Tools and Manufacture. 2002; 42: 985-995

5. Kadam, M.S and Pathak, S.S. Experimental Analysis and Comparative Performance of Coated and Uncoated Twist Drill Bit Dry Machining. International Journal of Research in Mechanical Engineering and Technology. 2011; 1: 2249-5762

6. Rao, S. and Dr. Lewlyn L.R. Impact Of Process factors On Twist Drill Wear In Machining gfrp Composites By Applying Taguchi Design Analysis And Anova Technique. International Journal of Advanced Technology \& Engineering Research (IJATER). 2014; 4: 2250-3536

7. Gaja, H. Analysis and modeling of depth-of-cut during end milling of deposited material. Masters Theses, Missouri University of Sceince and Technology. 2011.

8. Pontuale, G., Farrelly, F.A., Petri, A., and Pitolli, L. A statistical analysis of acoustic emission signals for tool condition monitoring (TCM). Acoustics Research Letters Online. 2003; 4(1): 1529-7853

9. xiqing, $\mathrm{M}$ and Chuangwen, $\mathrm{Xu}$. Tool wear monitoring of acoustic emission signals from milling processes. Proceedings of the 1 st International Workshop on Education Technology and Computer Science, ETCS. 2009; 1: 431-435

10. Karali, P. Acoustic Emission based Tool Condition Monitoring System in Drilling. Proceedings of the World Congress on Engineering. 2011; 3: 2078-0958

11. Issam, A.M. Drilling wear detection and classification using vibrations signals and artificial neural network. International Journal of Machine Tools and Manufacture. 2003; 43:707-720.

12. Jantunen, E. and Jokinen, H. Automated On-line Diagnosis of Cutting Tool Condition. International Journal of Flexible Automation and Integrated Manufacturing. 1996; 4:273-287.

13. Sambayi, P.M.K. Drill wear monitoring using instantaneous angular speed: A comparison with conventional technology used in drill monitoring systems. Masters Theses, University of Pretoria. 2012

14. Jie, X. Drill wear prediction and drilling conditionsrecognition with newly generated features. Ph.D Theses, Hiroshima University. 2014

15. Heinemann, R., Hinduja, S,. Barrow, G., Petuelli, G. The Performance of Small Diameter Twist Drills in Deep-Hole Drilling. Journal of Manufacturing Science and Engineering. 2006;128.

16. Jantunen, E. A summary of methods applied to tool condition monitoring in drilling. International Journal of Machine Tools and Manufacture. 2002; 42:997-1010.

17. Signal Processing Toolbox, For use with MATLAB User's guide. The Math Works USA. 1998

18. El-Wardany, T.I., Gao, D. and Elbestawi, M.A. Tool condition monitoring in drilling using vibration signature analysis. International Journal of Machine Tool and Manufacture. 1996; 36(6): 687711 